\title{
PEMANFAATAN APLIKASI SCRATCH SEBAGAI ALTERNATIF MEDIA BELAJAR SISWA "Z GENERATION" UNTUK GURU-GURU SDN 1 LABUAPI
}

\author{
M. Isnaini ${ }^{1)}$, Sukron Fujiaturahman²), Linda Sekar Utami'1), Zulkarnain ${ }^{1)}$, Khairil Anwar $^{1)}$, \\ Islahudin ${ }^{1)}$, Johri Sabaryati' ${ }^{1)}$ \\ 1)Pendidikan Fisika, FKIP, Universitas Muhammadiyah Mataram, Mataram, NTB, Indonesia \\ ${ }^{2)}$ Pendidikan Guru Sekolah Dasar, FKIP, Universitas Muhammadiyah Mataram, NTB, Indonesia \\ Corresponding author : M. Isnaini \\ E-mail : iskasipahune@gmail.com
}

Diterima 22 Oktober 2021, Direvisi 01 November 2021, Disetujui 01 November 2021

\begin{abstract}
ABSTRAK
Dewasa ini kita berada pada revolusi industri 4.0 yang pada dasarnya mengubah pola hidup, pola pikir, pola kerja yang berhubungan dengan satu sama lain. Perubahannya sangat drastis dibanding era revolusi sebelumnya. Sejalan dengan perkembangan revolusi industry 4.0, maka pendidikan saat ini tidak sesuai lagi dengan era revolusi industri 4.0. Pendidikan 4.0 secara keseluruhan akan berkontribusi dalam membangun generasi $Z$ atau igeneration dimana masa kanak-kanak Generasi $Z$ sudah melek teknologi, terutama smartphone dan PC. Sangat banyak strategi pembelajaran yang dapat digunakan untuk Genersi-Z. Pada prinsipnya strategi pedagogy dan andragogi yang bersifat universal tetap dapat digunakan, modifikasi dilakukan hanya pada bagian-bagian tertentu yang dapat dibantu dengan penggunaan fasilitas teknologi. Aplikasi yang digunakan dalam pelatihan ini adalah scratch junior. Aplikasi ini sangat mudah digunakan karena menggunakan blok seperti lego, serta tidak memerlukan keterampilan bahasa pemograman. Metode yang digunakan dalam pelatihan ini adalah metode demonstrasi \& praktik pembuatan media scratch. Pengumpulan data dilakukan menggunakan angket. Data menunjukan $80 \%$ responden mempunyai keinginan untuk membuat media pembelajaran berbasis animasi scratch yang lebih menarik \& belajar lebih mendalam.
\end{abstract}

Kata kunci: scratch; z generation; media belajar.

\begin{abstract}
Today we are in the industrial revolution 4.0, which changes the pattern of life, mindset, work patterns that relate to each other. The changes are very drastic compared to the previous revolutionary era. In line with the development of industrial revolution 4.0, education is no longer following the period of industrial revolution 4.0. Education 4.0 as a whole will contribute to building generation $Z$ or generation where Generation Z's childhood is technology literate, especially smartphones and PCs. Many learning strategies can be used for Generation Z. In principle, universal pedagogy and andragogy strategies can still be used; modifications are made only to certain parts that technological facilities can assist. The application used in this training is Scratch Junior. This application is effortless because it uses blocks like lego and does not require programming language skills. The method used in this training is a demonstration method \& practice of making scratch media. Data collection was carried out using a questionnaire. The data shows that $80 \%$ of respondents desire to make learning media based on scratch animations that are more interesting \& learn more deeply.
\end{abstract}

Keywords: scratch; z generation; learning media.

\section{PENDAHULUAN}

Proses pembelajaran merupakan rangkaian beberapa sistem yang saling berkaitan satu sama lainnya. Apabila salah satu sistem tidak dapat berfungsi maka sistem tidak dapat bekerja secara optimal. Proses pembelajaran akan lebih optimal jika dapat memanfaatkan media pembelajaran. Penggunaan media dalam proses pembelajaran diharapkan dapat membantu guru agar lebih mudah dalam mengajarkan materi kepada para siswa.

Dewasa ini kita berada pada revolusi industri 4.0 yang pada dasarnya mengubah pola hidup, pola pikir, pola kerja yang berhubungan dengan satu sama lain. Perubahannya sangat drastis dibanding era revolusi sebelumnya. Revolusi industri 4.0 ditandai dengan berkembangnya internet of atau for things yang diikuti teknologi baru dalam 
data dan sains, kecerdasan buatan, robotik, cloud, cetak tiga dimensi, dan teknologi nano (Ghufron, 2018).

Sejalan dengan perkembangan, maka pendidikan saat ini tidak sesuai lagi dengan perkembangan revolusi industri 4.0. Peserta didik di era pendidikan 4.0 berperan sebagai konektor, kreator, dan konstruktivis dalam memproduksi dan mengaplikasikan pengetahuan untuk berinovasi (Brown-Martin, 2018). Pendidikan 4.0 secara keseluruhan akan berkontribusi dalam membangun generasi $\mathbf{Z}$ atau igeneration. Generasi $Z$ didefinisikan sebagai generasi yang lahir antara tahun 19952010 sebagai kelanjutan dari generasi-generasi sebelumnya (Bencsik, Jubasz, HortvatbCsikos,2016). Masa kanak-kanak Generasi Z sudah melek teknologi, terutama smartphone dan PC, masa remaja Generasi Z ditandai dengan semakin populernya ponsel cerdas dan mengglobalnya jaringan komputer sehingga mereka bukan saja generasi digital tetapi sekaligus juga generasi internet. Sebuah riset yang dilakukan oleh lembaga independen menunujukkan hasil bahwa: "durasi fokus mahasiswa Gen-Z hanya sekitar 8-menit saja", hasil riset ini sangat mengejutkan karena durasi fokus Gen-Y (milenial) masih lebih panjang waktunya berkisar diantara 10 s.d.15 menit-an. (Hinduan, et al. 2017).

Merujuk studi yang dilakukan oleh Chun et al., (2016) dalam Tarkus (2018) sangat banyak strategi pembelajaran yang dapat digunakan untuk Genersi-Z. Pada prinsipnya strategi pedagogy dan andragogi yang bersifat universal tetap dapat digunakan, modifikasi dilakukan hanya pada bagian-bagian tertentu yang dapat dibantu dengan penggunaan fasilitas teknologi. Selain itu guru disarankan memiliki kemampuan digital dasar seperti: (1) merekam dan mengedit audio; (2) membuat video interaktif; (3) menggunakan media sosial dan membuat konten menarik; (4) membuat presentasi yang menarik; (5) menciptakan quiz yang non-traditional (Education Technology and Mobile Learning, 2016).

Suatu variasi pembelajaran menggunakan fasilitas teknologi dengan menggunakan komputer untuk menyajikan bahan-bahan pelajaran disebut pembelajaran berbantuan komputer (Computer Assisted Instruction = CAI). Salah satu jenis Computer Assisted Instruction (CAI) yang baru dan mudah digunakan adalah Scratch. Program Scatch adalah suatu program yang merupakan suatu simulasi yang digunakan untuk merancang hingga menganalisis, ditampilkan dalam bentuk animasi untuk mempertunjukkan fungsi atau prinsip dasar dari suatu pembelajaran.
Scratch adalah sebuah bahasa pemrograman yang tersedia secara gratis dan dibuat oleh Lifelong Kindergarten Group dari Massachusetts Institute of Technology (MIT) dengan lebih dari 7 juta pengguna terdaftar. Versi terbaru Scratch, Scratch 3.2. dapat digunakan secara online di http://scratch.mit.edu/create/ juga dapat diunduh untuk dikerjakan secara offline. Scratch 2 dapat di unduh di https://scratch.mit.edu/download.

Scratch didesain untuk menjadi asyik, edukatif, dan mudah untuk dipelajari. Scratch bisa digunakan untuk membuat cerita interaktif, permainan, seni (art), simulator, dan masih banyak lagi. Scratch bahkan mempunyai editor menggambar dan editor suara sendiri. Pengguna dapat menyusun sebuah program di Scratch dengan menarik dan menggeser balokbalok dari Palet Balok kemudian menggabungkan mereka ke balok lain seperti puzzle jigsaw.

Struktur dari beberapa balok atau lebih disebut skrip. Metode pemrograman ini (menulis kode dengan balok) juga bisa disebut "pemograman geser dan menaruh", atau, dalam Bahasa Inggrisnya, "drag and drop programming". Scratch digunakan di sekolahsekolah di segala penjuru dunia sebagai media untuk mengenalkan pemrograman dasar ke anak-anak. Scratch juga digunakan di luar sekolah. Anak-anak, dan bahkan orang dewasa, menambah pengertian tentang berbagai bentuk pemrograman lewat Scratch. Di Indonesia, Scratch banyak digunakan kursus pemrograman komputer sebagai media pembelajaran

Penelitian- penelitian terbaru menunjukan bahwa penggunaan aplikasi Scratch memberikan dampak yang baik dalam pembelajaran. Seperti penelitian Nugroho, Kristian Andi (2019) menunjukan bahwa aplikasi scratch yang dikembangkan sangat baik digunakan dalam proses pembelajaran pada siswa kelas IV sekolah dasar. Penelitian Mardiyanto, Haris (2018) juga menunjukan bahwa hasil uji coba lapangan pada aplikasi scratch menghasilkan rerata skor 4,1 dengan kategori baik. Penelitian Toheri, Nuraenafisah (2012) menyatakan bahwa penggunaan scratch berpengaruh terhadap kreativitas berfikir matematis. Dan banyak penelitian lain yang mendukung penggunaan aplikasi scratch.

Sekolah Dasar Negeri 1 Labu Api merupakan salah satu sekolah dasar unggulan di Lombok Barat. SDN 1 Labu Api memiliki 10 orang guru dan sarana prasarana yang memadai seperti ruang kelas maupun media pembelajaran. Sapras yang dimiliki selain ruang kelas juga memiliki perpustakaan dan ruang 
aula. Media pembelajaran yang dimiliki oleh SDN 1 Labu Api adalah media pembelajaran yang bersifat konvensional, seperti peralatan KIT, Video pembelajaran, Poster/ Buku. pada masa pandemic ini, guru guru telah memanfaatkan gaget/ HP sebagai sarana pembelajaran, tetapi dalam skala terbatas untuk membagi materi pembelajaran konvensional atau pengumpulan tugas sehingga siswa cepat merasa bosan. Selain itu Guru-guru SDN 1 Labu Api belum memperoleh pelatihan yang memadai untuk menerapkan pembelajaran era revolusi industry 4.0 sehingga sesuai untuk siswa SD "Z generation" yang sangat erat dengan teknologi.

Salah satu indikator kompetensi guru adalah kompetensi Teknologi Informasi dan Komunikasi (TIK). Kompetensi TIK guru adalah kemampuan guru dalam mengembangkan inovasi pembelajaran dengan memanfaatkan TIK baik dalam merencanakan, melaksanakan, maupun mengevaluasi pembelajaran, baik pada aspek kompetensi pedagogi, personal, profesional, maupun sosial. Menurut Peraturan Menteri Pendidikan Nasional Nomor 16 Tahun 2007, kompetensi TIK bagi guru sekurangkurangnya mempunyai dua fungsi, yaitu TIK sebagai pengembangan diri dan TIK sebagai penunjang proses pembelajaran (Niarsa, 2013).

Data beberapa penelitian menunjukan bahwa kompetensi TIK guru SD masih minim. Seperti penelitian yang dilakukan Niarsa (2013) menunjukan bahwa tingkat penguasaan TIK di Guru SDN 1 Ledok Blora dalam kategori cukup. Selain itu hasil wawancara Batubara, S.D (2017) di Banjarmasin khususnya guru yang berumur 45 tahun, tidak mampu membuat slide powerpoint dengan baik, menggunakan perangkat LCD Proyektor, dan kondigital audio dan video dalam pembelajaran.

Hasil penelitian Wimartono, dkk (2016) mengungkapkan bahwa faktor-faktor yang mempengaruhi seorang guru dalam menggunakan teknologi informasi adalah: faktor sosial dengan koefisien sebesar 46,0\%, kesesuaian tugas sebesar $30 \%$, kondisi yang memfasilitasi sebesar $-10,1 \%$ (berkontribusi negatif), Kompleksitas sebesar $-48,0 \%$ (berkontribusi negatif), Konsekuensi jangka panjang sebesar $14,0 \%$, dan faktor Affect (perasaan individu) sebesar 20,4\%. Faktor kondisi yang memfasilitasi berkontribusi negatif berarti kehadiran perangkat TIK belum mendapat respon yang positif dari guru. Adapun faktor kompleksitas akan menurun apabila seorang guru telah mampu menjalankan aplikasi-aplikasi atau software yang diperlukan dalam menjalankan profesinya.

Hasil penelitian-penelitian tersebut sejalan dengan wawancara penulis di SDN 1 Labu Api.
Guru-guru SDN 1 Labu Api masih kurang termotivasi untuk membuat media pembelajaran berbasis TIK, terutama penggunaan aplikasi-aplikasi atau software pembelajaran. Mereka menganggap aplikasi atau software tersebut ribet \& susah digunakan sehingga guru-guru lebih cenderung menggunakan media pembelajaran yang sudah ada seperti KIT pemebelajaran.

\section{METODE}

Metode yang digunakan dalam kegiatan pengabdian adalah metode ceramah, demonstrasi \& praktik. Kegiatan ceramah dilaksanakan untuk menyampaikan materi awal tentang perkembangan strategi belajar " $Z$ generation". Metode demonstrasi digunakan untuk menjelaskan cara \& tools-tools yang ada pada scratch, memperagakan langkah-langkah proses pembuatan media pembelajaran berbasis aplikasi scratch. Kemudian dilanjutkan dengan praktik secara langsung pembuatan media pembelajaran berbasis aplikasi scratch tersebut sesuai mata pelajaran yang diajarkan masing-masing.

Kegiatan pengabdian yang dilaksanakan pada tanggal 8 maret 2021 dibagi menjadi dua termin. Termin pertama adalah penyampaian materi yaitu (1) perkembangan \& tantangan pembelajaran $Z$ generation \& (2) pengenalan aplikasi scratch. Termin kedua adalah praktik pembuatan media pembelajaran berbasis scratch.

Partisipasi mitra Sekolah Dasar Negeri 1 Labuapi dalam pelaksanaan program ini dengan mempersiapkan administrasi kegiatan, seperti surat undangan untuk guru, surat kesediaan pelaksanaan pengabdian. Dukungan lain mitra dalam kegiatan ini dengan menyiapkan sapras yang dibutuhkan. Sapras yang disediakan oleh mitra adalah menyiapkan ruang TIK dan peralatan penunjang seperti proyektor, Wifi.

\section{HASIL DAN PEMBAHASAN}

Jumlah peserta yang terlibat dalam kegiatan ini adalah 7 orang guru dari berbagai kelas/ mapel. Tema pengabdian kepada masyarkat adalah Pelatihan penggunaan aplikasi scratch sebagai media belajar siswa Z Generation adalah ingin memberikan pengetahuan kepada para guru-guru SDN 1 Labuapi tentang pemanfatan software aplikasi scratch sebagai sarana untuk membuat media pembelajaran berbasis animasi sehingga diharapakan proses penyampaian materi belajar bisa lebih mudah dipahami oleh para siswa.

Proses kegiatan ini berjalan dengan lancar selain itu juga peserta dengan serius dan 
antusias mengikuti pelatihan dari awal sampai akhir. Proses pelatihan dipandu oleh Dosen yang dibantu tim administrasi mahasiswa dengan menggunakan layar dan projector di ruang TIK SDN 1 Labuapi, beberapa Laptop \& Gadget/ HP sehingga sangat membantu penyampaian materi pelatihan. Selain itu peserta juga sangat aktif bertanya khususnya mengenai hal-hal yang bersifat teknis seperti cara membuat animasi gerak, memasukkan suara dan mengganti background animasi.

Termin pertama adalah memberi pemahaman perubahan gaya belajar siswa setiap generasi, khusunya Z Generation. Pada kegiatan ini seluruh peserta menyatakan setuju dengan pemaparan dari pemateri, sehingga diperlukan pelatihan yang sesuai. Yang dilanjutkan dengan pemateri memberikan penjelasan \& pengenalan aplikasi scratch yang bertujuan agar peserta memiliki pengetahuan dalam menjalankan aplikasi scratch junior. Pada pengenalan aplikasi ini diberikan pengetahuan tentang tampilan awal scratch, sehingga guru-guru mengenal bagian-bagian scratch junior, tools yang digunakan dalam apliksi scratch. Selanjutnya pemateri memberikan langkah-langkah praktis untuk memulai membuat media pembelajaran berbasis animasi komputer, dari mulai membuat gambar materi pembelajaran sampai memasukkan suara dan background.

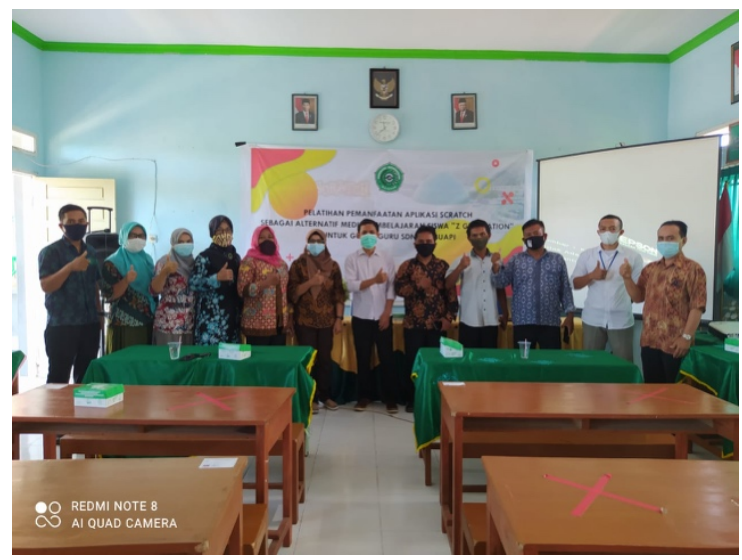

Gambar 1. Foto Pelaksanaan Kegiatan

Termin kedua adalah kegiatan inti pengabdian dimana peserta melakukan praktik secara langsung dengan pendampingan oleh dosen pelatihan. Pada kegiatan ini guru-guru diberikan pelatihan pembuatan media pembelajaran berbasis scratch junior dimana guru-guru mengikuti setiap langkah pembuatan media yang diberikan oleh tim pengabdian. Setelah guru-guru mencoba penggunaan aplikasi scratch untuk membuat media pembelajaran, mereka diberi kesempatan untuk membuat media scratch sesuai dengan keterampilan yang telah meraka peroleh. Pada bagian ini tidak semua guru dapat meyelesaikan pembuatan media scratch, meskipun tidak semua peserta dapat menyelesaikan atau membuat suatu media pembelajaran berbasis scrach secara utuh dikarenakan perlunya memikirkan konsep materi yang tepat dan juga keterbatasan waktu pelatihan, akan tetapi konsep dasar membuat media pembelajaran berbasis scratch sudah mereka pahami. Selain itu diberikan juga buku pedoman penggunaan aplikasi scratch, agar guru-guru dapat dengan mudah mengingat kembali pelatihan yang telah dilakukan.

Setelah diberikan pelatihan tentang pemanfaatan aplikasi scratch untuk membuat media pembelajaran siswa Z Generation, peserta mulai memahami langkah dan proses pembuatan media pembelajaran berbasis scratch serta mengetahui tools apa yang digunakan dalam aplikasi scratch untuk membuat media pembelajaran dengan mudah. selanjutnya peserta diberikan kuesioner yang merupakan indikator mengenai pembahaman penggunaan aplikasi scratch untuk membuat media pembelajaran berbasis animasi komputeroleh peserta pelatihan. Berikut isi dan hasil kuesioner ditunjukkan pada Tabel 1.

Tabel 1. Hasil pengisian kuesioner

\begin{tabular}{|c|c|c|c|c|}
\hline No & Isi Pertanyaan & $\begin{array}{l}\text { Sangat } \\
\text { baik }\end{array}$ & baik & $\begin{array}{l}\text { kurang } \\
\text { baik }\end{array}$ \\
\hline 1 & $\begin{array}{l}\text { Apakah anda } \\
\text { menyukai } \\
\text { pelatihan ini }\end{array}$ & 7 & & \\
\hline 2 & $\begin{array}{l}\text { Apakah pelatihan } \\
\text { memberi manfaat } \\
\text { bagi peserta }\end{array}$ & 4 & 3 & \\
\hline 3 & $\begin{array}{l}\text { Apakah peserta } \\
\text { sudah memahami } \\
\text { proses } \\
\text { pembuatanmedia } \\
\text { pembelajaran } \\
\text { berbasis scratch }\end{array}$ & 5 & 2 & \\
\hline 4 & $\begin{array}{l}\text { Apakah peserta } \\
\text { masih berfikir } \\
\text { membuat media } \\
\text { pembelajaran } \\
\text { animasi komputer } \\
\text { edukasi } \\
\text { sederhana } \\
\text { berbasisi scratch } \\
\text { itu sulit? }\end{array}$ & 4 & 3 & \\
\hline 5 & $\begin{array}{l}\text { Apakah peserta } \\
\text { berkeinginan } \\
\text { membuat media } \\
\text { pembelajaran } \\
\text { berbasis animasi } \\
\text { scratch yang lebih } \\
\text { menarik? }\end{array}$ & 2 & 4 & 1 \\
\hline 6 & $\begin{array}{l}\text { Apakah peserta } \\
\text { sudah memahami } \\
\text { pemrograman } \\
\text { visual scratch }\end{array}$ & 3 & 4 & \\
\hline
\end{tabular}




\begin{tabular}{|c|c|c|c|c|}
\hline 7 & $\begin{array}{l}\text { Apakah peserta } \\
\text { tertarik untuk } \\
\text { belajar } \\
\text { pemrograman } \\
\text { visual scratch lebih } \\
\text { mendalam }\end{array}$ & 2 & 4 & 1 \\
\hline 8 & $\begin{array}{l}\text { Apakah } \\
\text { pemrograman } \\
\text { visual scratch } \\
\text { terasa sulit }\end{array}$ & 3 & 4 & \\
\hline 9 & $\begin{array}{l}\text { Apakah peserta } \\
\text { perlu memahami } \\
\text { bahasa } \\
\text { pemrograman } \\
\text { tertentu untuk bisa } \\
\text { memahami } \\
\text { pemrograman } \\
\text { visual untuk media } \\
\text { pembelajaran? }\end{array}$ & 3 & 4 & \\
\hline
\end{tabular}

Dari data kuesioner terlihat ada dua aspek kuesioner yang mendapat respon kurang yaitu keinginan untuk belajar lebih mendalam \& keinginan untuk membuat media pembelajaran berbasis komputer yang lebih baik. Sedangkan kuesioner yang lain mendapat jawaban sangat baik dan baik. Hal ini menandakan tidak semua peserta mempunyai keinginan untuk terus menggunakan media pembelajaran scratch ini, lebih umumnya teknologi/ komputer. Sejalan dengan data ini, hasil penelitian sebelumnya menunjukan kecenderungan yang sama. Penyebabnya bermacam-macam, mulai dari motivasi guru untuk membuat sendiri media pembelajaran, susah menyiapkan peralatan/ laptop untuk membuat media scratch, tidak memiliki waktu cukup untuk membuat meida dan lain sebagainya.

\section{SIMPULAN DAN SARAN}

Berdasarkan data yang diperoleh melalu angket, $80 \%$ responden mempunyai keinginan untuk membuat media pembelajaran berbasis animasi scratch yang lebih menarik \& belajar lebih mendalam sedang sisanya memiliki berbagai kendala diantaranya motivasi guru untuk membuat sendiri media pembelajaran, susah menyiapkan peralatan/ laptop untuk membuat media scratch, tidak memiliki waktu cukup untuk membuat media.

\section{UCAPAN TERIMAKASIH}

Tim pengabdian mengucapkan terima kasih kepada semua pihak yang membantu atas terlaksananya kegiatan ini diantaranya yaitu Lembaga Penenelitian dan Pengabdian kepada Masyarakat Universitas Muhammadiyah Mataram \& SDN 1 Labuapi

\section{DAFTAR RUJUKAN}

Sukardi, K, D. (2002). Pengantar Pelaksanaan Program Bimbingan dan Konseling di Sekolah. Jakarta: Rineka Cipta.

Bencsik, A.H.C. (2016). Y and Z Generation at Workplaces. Journal of Competitiveness, 90-106

Brown-Martin, G. (2017). Education and The Fourth Industrial Revolution. Tersedia di https://www. groupemediaatfo.org/wpcontent/uploads/2017/12/ FINAL.

Chun, C., K Dudoit, S. Fujihara, M. Gerschenson, A. Kennedy, B. Koanui, V. Ogata, dan J. Sterns. 2016. Teaching generation $Z$ at the University of Hawai't. Available at https://papers.iafor.org/submission342 $\underline{021}$.

Ghufron, M.A. (2018). Revolusi Industri 4.0: Tantangan, Peluang dan Solusi bagi Dunia Pendidikan. Makalah. Seminar Nasional dan Diskusi Panel Multidisiplin Hasil Penelitian \& Pengabdian kepada Masyarakat tanggal 2 Agustus 2018. Jakarta: LPPM Unindra.

Hinduan, Z.r., M.I. Agia, dan S. Kholiq. 2017. Generation $Z$ in Indonesia: Psychological Capital, Work Value, and Learning Style. Universitas Padjadjaran.

Mardiyanto, Haris (2018). Pengembangan media pembelajaran scratch pada mata pelajaran IPA kelas $V$ materi penghematan air. Yogyakarta. Universitas Sanat Dharma. Skripsi. 